\title{
Closing Moves of Dyadic Chat Room Talk in Chinese Between Family Members
}

\author{
WU Xi-yan \\ Hubei University, Wuhan, China
}

\begin{abstract}
Computer-mediated communication has become a way of living in modern society. Little research has been conducted on dyadic chat room talk between familiars. Conversation analysis was employed to analyze data collected from the author's friends and colleagues who conversed via QQ.com in Chinese with their family members over a period of half a year. It was revealed that dyadic chat room talk between family members observed three closing moves: closing implicative topic(s), initiation of new topics (optional), and an exchange of terminal close. But due to intimacy, it featured the exclusion of pre-closings and a typing of the talk as in the general schema, the moves out of closing such as arrangements or solicitude and the refusal to the initiation of closing.
\end{abstract}

Keywords: closing moves, dyadic chat room talk, online family discourse

\section{Introduction}

Social interaction is a vital part of social life and a solid foundation of personal self-actualization (Neviarouskaya, Prendinger, \& Ishizuka, 2007). In daily conversations, people use words, body language, and other symbols to exchange information, express emotions and feelings, establish certain interpersonal relationships, entertain themselves, and even perform acts. In this digital age, one cannot live without the Internet, which has been exerting a great influence on people's interaction. The Internet seems to have created a new way of doing old things (Tyler, 2002). Its effects are evidently discerned in aspects of the user's psychological well-being, the formation and maintenance of personal relationships, group memberships and social identity, the workplace, and community involvement (Bargh \& McKenna, 2004). Instead of face-to-face communication and traditional telephone conversations, online chat, also called computer-mediated communication (CMC), has become a way of living. On the bus, in the street, at the post office, or even in the classroom, online chat is omnipresent, going on ever and forever.

Internet chat rooms, which are defined as virtual "spaces" in the cyber world where people assemble for social interactions (Greenfield \& Subrahmanyam, 2003), have become the setting for "all manner of social interaction, from café style conversation to the political discussion of members of expatriate communities, to live reports by computer users in countries in which crises are taking place" (Werry, 1996, p. 48, as cited in Parrish, 2002, Introduction, para. 3). This type of talk can occur between strangers, friends, and even family members. In modern times, mobility is typical of very society, thus online communication bringing convenience and shortening the distance between people.

WU Xi-yan, associate professor, M.A., School of Foreign Languages, Hubei University. 
Crystal (2006) distinguishes two types of online chat: asynchronic and synchronic. The former means that "individual contributions to a group are saved and distributed as they come in, which may be read at any time and separated by any period of time" (Crystal, 2006, pp. 139-140). Asynchronic chat relieves the addressee of time pressure though an immediate response is usually delayed. The latter refers to electronic conversations that are taking place in real time (Ibid.). Real-time online interaction occurs in group or one-to-one chat between people who may or may not know each other in real life (Cambell \& Wickman, 2000).

Online chat has been attracting thousands of millions of people around the globe to meet and get acquainted. Apart from strangers, familiars like family members have taken to it as well. Strangers resort to it to make friends and express themselves (Johnson, Cooper, \& Chin, 2009). Students avail themselves of it to learn more effectively (Guzley, Avanzino, \& Bor, 2001; Sadler, 2007; Freiermuth \& Huang, 2012). It is true that an increasing number of families use it to maintain affectionate bonds and enhance their relationships, especially when they are thousands of miles apart. Thus their online conversations deserve a shot in the research on CMC.

Family discourse is significant not only because everyone experiences spoken interaction with family members (or caregivers), but also because the types of miscommunications and strategies found in discursive interaction within the family unit are also evident in the larger society. The family is, as such, a microcosm of many of the relationships and interactions in society at large, in and across all social groups. (Johnson, 2007, p. 1)

Though online family discourse exhibits linguistic and structural properties similar to those of other means of communication, it is unique in its own right. Online chat discourse has been the area of interest from a linguistic perspective (Werry, 1996; Nishimura, 2003; Greenfield \& Subrahmanyam, 2003; Ecker, 2011). Structurally, it differs from everyday conversations. Turn-talking and topic management, and opening and closing moves have been popular with researchers. Closings of conversations have been one of the foci of conversation analysis. Openings are an excellent starting point to investigate how interaction functions to initiate and develop relationships (Rintel, Mulholland, \& Pittam, 2001, Introduction, para. 2). Every conversation must have a closing. Closings are also a venue for furthering or ending relationships. As a unique variety of conversation (Noblia, 1998) or discourse (Cambell \& Wickman, 2000), synchronic chat room talk may exhibit unique structural organization of closing moves.

\section{Related Literature}

\section{Studies on Turn-Taking and Topic Management}

Synchronic chat room talk has been the research focus of a host of studies which adopt a CA (Conversation Analysis) approach. Previous studies mainly examine turn-taking and topic management: (1) dispersed and intermingled adjacent pairs (Herring,1999; Negretti, 1999; Sitaraman, 2006); (2) overlapping exchanges (Herring, 1999); (3) topic decay (Herring, 1999); (4) disrupted and discontinuous turn-taking (Negretti, 1999; O’Neill \& Martin, 2003); (5) non-dyadic exchanges (Parrish, 2002); (6) multiple and simultaneous threads of conversation (Negretti, 1999; Parrish, 2002; Greenfield \& Subrahmanyam, 2003; O'Neill \& Martin, 2003; Sitaraman, 2006); (7) short turns (Sitaraman, 2006); and (8) fluid topic initiation and change (O’Neill \& Martin, 2003). 


\section{Studies in Opening and Closing Moves}

A few studies explore online chat openings. Negretti (1999) finds that web chat openings contain the basic sequences such as summons-answer, identification, greeting sequences but display special features like identification as "a self-introduction aimed at having one's presence acknowledged by the other participants" (Negretti, 1999, p. 83). Rintel and Pittam (1997) identify four Internet Relay Chat (IRC) opening moves: server announcement of the user presence, "exchange of exploratory/initiatory linguistic tokens", "textualized exchange" of "greeting" (optional depending on relationship), and "transition signals for moving to the medial phase" (as cited in Rintel, Mulholland, \& Pittam, 2001, Previous research on IRC openings, para. 2). Rintel, Mulholland, and Pittam (2001) examine three stages of IRC: presence recognition, initiation, and response. These findings exhibit similarity to sequences in telephone openings.

However, little research has been done on the closing moves of chat room talk. Negretti (1999) reports that "in many cases, pre-closings present some kind of justification or reason why the speaker is leaving" and "sometimes, pre-closing and closing take place in the same turn" (p. 84). This area needs further exploration, which necessitates the present research.

\section{Theoretical Framework}

Since no established framework for closing moves of chat room talk has been identified and the extant research (Negretti, 1999) shows that it exhibits features similar to those in telephone conversations, this study adopts as the theoretical orientation the general schema for closing moves in telephone conversations. Shegloff and Sacks (1973) propose the archetype closing: four turns of conversational closing - two pre-closing and two closing moves (Button, 1987). "The first and second turns typically consist of items such as 'okay' and 'alright' and the third and fourth turns of items such as 'bye' and 'goodbye" (Button, 1987, p. 102). Levinson summarizes the closing sections of conversation, which is relatively comprehensive: (1) "closing implicative topics" such as making arrangements, giving regards, etc.; (2) "passing turns with pre-closing items" like "Okay" or "All right", etc.; (3) "a typing of the call" "as a favor" like "Thank you" or "as a checking up on one's state of health" (optional); and (4) an exchange of terminal close such as "Bye", "Cheers", etc. (Levinson, 1983, p. 317).

However, in reality, closing sequences will be more complicated and situation-bound, which means that the moves may not be so neatly organized. It is not the case that online chat will come to an end once a closing move has been initiated (Button, 1987). To explain how this happens, Button (1987) examines sequence types in closing that are intended to move out of closings after the pre-closing moves: arrangements, which may overspill into closings or are reintroduced; back-references, which retopicalize the material referred to before and may constitute a drastic moves out of the closing; topic initial elicitors, oriented to eliciting a newsworthy item in-conversation objects, which does not aim to introduce new material but displays a possibility of conversational continuation; solicitudes, which are meant to show concern for the other participant and others concerned; reasons for calls and appreciations.

The present research, based on Levinson's framework and Button's classification of the categories of sequence types in closings, aims to examine and explain the characteristics of closings in dyadic online chat room talk between family members. 


\section{The Present Study}

\section{Research Questions}

The aforementioned overview shows that: (1) Precious research has been largely devoted to turn-taking, topic management and openings of chat room talk, but little research is conducted on its closing moves; (2) much has been said about multi-participant online chat, but little is discussed about dyadic chat room talk; and (3) most of the studies are about people who may not know each other, but few studies focus on familiars, such as family members (Sitaraman, 2006) and close friends. To bridge the gap, this study is intended to identify the closing moves of dyadic chat room talk between family members, adding to the body of knowledge of conversation in general and online communication in particular.

Accordingly, the following questions will be addressed:

(1) What closing moves are conducted in dyadic chat room talk between family members?

(2) What are the unique characteristics of closing moves of dyadic chat room talk between family members?

\section{Methods}

Chat room talk is regarded as a unique variety of conversation (Noblia, 1998) or discourse (Cambell \& Wickman, 2000). The written conversation online is carried out very quickly and calls for little editing, and thus it is, like oral conversation, spontaneous and locally organized (Sitaraman, 2006, Introduction, para. 1).

This study adopts CA (conversation analysis) in data analysis. Though CA is a method of analyzing spoken conversation, it has been proved applicable to the analysis of turn taking, repair and sequencing of synchronic chat room talk (Örnberg, 2003), because CA can "readily be applied to sequences of text chat, when we consider how it is temporally produced and shared" (O’Neill \& Martin, 2003, Method, para. 1). Since the data in the present research took the form of written text chat, many features, such as intonation, pauses, hesitations, etc., will be missing.

The study employed the categories and concepts about closing moves by Levinson (1983) and about moving out of closing by Button (1987) to analyze data. The data were collected from the author's friends and colleagues who conducted dyadic chat room talk via QQ.com in Chinese with their family members over a period of half a year. Since family interaction is quite private and personal, the author contacted and talked to her friends and colleagues about the research purpose and the use of data. A written consent was signed which stressed that the author would never use their data for purposes other than this study. The data analyzed were checked by all the people concerned. Since text chat can be automatically stored, retrieval is possible at any time. Therefore, there is little researcher bias in data collection. The data was translated into English.

\section{Data Analysis and Discussion}

The typical features of closing moves can be illustrated in the following two examples. Look at example (1) $(\mathrm{H}=$ husband, $\mathrm{W}=$ wife, $\mathrm{L}=$ line) (see Table 1$)$ : 
Table 1

Closing Moves With a New Topic

\begin{tabular}{|l|l|}
\hline L1:19:24:06[W]: 老公, 我要走了 & Dear, I will be off. [closing implicative] \\
\hline L2:19:24:30[W]: 晚上打电话, 好吗 & Call you tonight, OK. [closing implicative] \\
\hline L3:19:24:46[W]: 你要多吃点 & You'd better eat more. [closing implicative] \\
\hline L4:19:24:46[H]: 好的 & OK. [consent] \\
\hline L5:19:24:51[H]: 你去吧 & You go ahead. [consent] \\
\hline L6:19:24:54[W]: 我们还没有吃饭了 & We haven't had supper yet. \\
\hline L7:19:25:02[H]: 快去吧 & Go and have it. \\
\hline L8:19:25:04[W]: 我吃点饼干就行了 & Some biscuits will do. \\
\hline L9:19:25:07[H]: 我也关; 哦 & I'll be offline too; [consent] I see. \\
\hline L10:19:25:19[H]: 这样不行, 要吃菜 & It's not good. Have some vegetables. \\
\hline L11:19:25:20[W]: 打电话吗 & Call you later. [closing implicative] \\
\hline L12:19:25:28[H]: 好的 & Ok. [consent] \\
\hline L13:19:25:33[H]: 88 & Bye-bye. [first terminal close] \\
\hline L14: $19: 25: 34[\mathrm{~W}]:$ 拜拜 & Bye-bye. [second terminal close] \\
\hline
\end{tabular}

In this example, the closing down of the previous topic spans the first three lines by mentioning three implicative topics: necessity to go (line 1), making an arrangement of calling the husband (line 2), and expressing solicitude (line 3), which are meant to bring an end to the talk. The wife's attempt to terminate the talk is responded with the husband's consent which spreads over three discontinuous lines (lines 4, 5, and 9), showing the husband's "orientation towards closing" (Pavlidou, 2002, p. 212). But in-between, a new topic about supper is raised by the wife until another pair of closing initiation and consent (lines 11 and 12) is produced. Then the talk ends with an exchange of terminal close (lines 13 and 14).

Look at example (2) $(\mathrm{H}=$ husband, $\mathrm{W}=$ wife) (see Table 2$)$ :

Table 2

Closing Moves With Refusal and a New Topic

\begin{tabular}{|l|l|}
\hline $15: 17: 45[\mathrm{~W}]:$ 我们先学习, 待会儿再聊吧 & $\begin{array}{l}\text { Shall we study for the moment and talk later? } \\
\text { [closing implicative] }\end{array}$ \\
\hline $15: 17: 52[\mathrm{H}]:$ 不! & No! [refusal] \\
\hline $\begin{array}{l}\text { 15:17:58[H]: 我等一会就要下了 } \\
\ldots\end{array}$ & $\begin{array}{l}\text { I will be offline in a moment. } \\
\text { (41 lines later) }\end{array}$ \\
\hline $15: 30: 44[\mathrm{~W}]:$ 那你去忙吧, 晚上再打电话 & $\begin{array}{l}\text { You do your work first. Call you later tonight? } \\
\text { [closing implicative] }\end{array}$ \\
\hline $15: 30: 50[\mathrm{H}]:$ 不用了 & No need (to call me). [refusal] \\
\hline $15: 30: 58[\mathrm{H}]:$ ! 现在聊一会我就下 & $\begin{array}{l}\text { ! We chat for a while and I will get offline. } \\
\text { (79 lines later) }\end{array}$ \\
\hline $15: 53: 55[\mathrm{~W}]:$ 快到4点了, 我们晚上再聊吧 & $\begin{array}{l}\text { It is nearly four. Let's talk tonight. } \\
\text { [closing implicative] }\end{array}$ \\
\hline $15: 54: 12[\mathrm{H}]:$ 好的! 妈妈去接宝贝了 & $\begin{array}{l}\text { OK! [consent] Mum's gone to bring our daughter back. } \\
\text { (34 lines later) }\end{array}$ \\
\hline $16: 06: 31[\mathrm{~W}]:$ 现在4点了, 我们晚上再聊吧 & $\begin{array}{l}\text { It's 4 o'clock. Let's talk tonight. } \\
\text { [closing implicative] }\end{array}$ \\
\hline $16: 06: 37[\mathrm{H}]:$ 好的! 888 & OK. [consent] Bye-bye. [first terminal close] \\
\hline $16: 06: 40[\mathrm{~W}]:$ 拜拜 & Bye-bye. [second terminal close] \\
\hline
\end{tabular}

"Any attempt to close down a topic must be confirmed by the other partner" (Brinker \& Sager, 1989, as cited in Pavlidou, 2002, p. 202). In this example, the wife suggests twice ending the conversation, but the 
husband's refusal constitutes a drastic move out of closing, the first of which spans 41 lines and the second 79 lines. The third time the closing implicative topic is accepted by the husband but a new topic about Mum is raised, which spreads over 34 lines until the fourth closing implicative topic. It is then taken up and followed by an exchange of terminal close. All the closing implicative topics here are about making arrangements.

\section{Conclusion}

In sum, dyadic chat room talk between family members observes the following closing moves: closing implicative topic(s), initiation of new topics (optional), and an exchange of terminal close. By comparison, it exhibits particular features: (1) It excludes pre-closings and a typing of the talk as in the general schema by Levinson (1983); (2) it may start with moves out of closing such as arrangements or solicitude (Button, 1987); and (3) initiation of closing can be met with refusal from the partner, which is justified in view of their intimate relationship.

The general schema of closing moves is an "interactionally economic solution, which pays minimal attention to the relationship aspect of communication" (Pavlidou, 2002, p. 224), which may fail to capture the family chat room talk that is affectively progressing.

\section{References}

Bargh, J. A., \& McKenna, K. Y. A. (2004). The Internet and social life. Annual Review of Psychology, 55, 573-590.

Button, G. (1987). Moving out of closings. In G. Button and J. R. E. Lee (Eds.), Talk and social organization (pp. 101-151). England: Multilingual Matters.

Cambell, C., \& Wickman, S. A. (2000). Familiars in a strange land: A case study of friends chatting online. Journal of Media and Culture, 3(4), 1-8.

Crystal, D. (2006). Language and the Internet. Cambridge: Cambridge University Press.

Ecker, R. (2011). Creation of Internet relay chat nicknames and their usage in English chat room discourse. Linguistik Online, 50(6), 3-29.

Freiermuth, M. R., \& Huang, H. C. (2012). Bringing Japan and Taiwan closer electronically: A look at an intercultural online synchronic chat task and its effect on motivation. Language Teaching Research, 16(1), 61-88.

Greenfield, P. M., \& Subrahmanyam, K. (2003). Online discourse in a teen chat room: New codes and new modes of coherence in a visual medium. Journal of Applied Developmental Psychology, 24, 713-738.

Guzley, R. M., Avanzino, S., \& Bor, A. (2001). Simulated computer-mediated/video-interactive distance learning: A test of motivation, interaction satisfaction, delivery, learning \& perceived effectiveness. $J C M C, 6(3)$.

Herring, S. C. (1999). Interactional coherence in CMC. JCMC, 4(4).

Johnson, N. A., Cooper, R. B., \& Chin, W. W. (2009). Anger and flaming in computer-mediated negotiation among strangers. Decision Support Systems, 46(3), 660-672.

Johnson, R. (2007). The co-construction of roles and patterns of interaction in family discourse. Working Papers in TESOL \& Applied Linguistics, 7(2), 1-26.

Levinson, S. C. (1983). Pragmatics. Cambridge: Cambridge University Press.

Negretti, R. (1999). Web-based activities and SLA: A conversational analysis research approach. Language Learning \& Technology, 3(1), 75-87.

Neviarouskaya, A., Prendinger, H., \& Ishizuka, M. (2007). Analysis of affect expressed through the evolving language of online communication. In Proceedings of IUI (pp. 278-281). ACM Press.

Nishimura, Y. (2003). Linguistic innovations and interactional features of casual online communication in Japanese. JCMC, 9(1).

Noblia, M. V. (1998). The computer-mediated communication, a new way of understanding the language. IRISS '98: Conference Papers. International Conference, Bristol, UK. http://www.intute.ac.uk/socialsciences/archive/iriss/papers/paper22.htm

O’Neill, J., \& Martin, D. (2003). Text chat in action. Retrieved from http://www.dirc.org.uk/publications/inproceedings/papers/93.pdf 
Örnberg, T. (2003). Written conversation: An investigation of the oral features of text chat through conversation analysis. Retrieved from http://www.humlab.umu.se/files/pdf/conv_analysis.pdf

Parrish, R. (2002). Conversational analysis of Internet chat rooms. Retrieved from http://www.polisci.wisc.edu/ rdparrish/Chat\%20Rooms\%20for\%20Web\%20Site.htm

Pavlidou, T. S. (2002). Moving towards closing: Greek telephone calls between familiars. In K. K. Luke and T. S. Pavlidou (Eds.), Telephone calls (pp. 201-229). Amsterdam/Philadelphia: John Benjamins Publishing Company.

Rintel, E. S., Mulholland, J., \& Pittam, J. (2001). First things first: Internet relay chat openings. JCMC, 6(3).

Sadler, R. (2007). Computer-Mediated Communication and a Cautionary Tale of Two Cities. CALICO Journal, 25(1), 11-30.

Sitaraman, S. (2006). Chat analysis: Applying conversation analysis to Internet chat. Retrieved from http://72.14.235.104/search?q=cache:4b5SpO_FbNcJ:www.studisurf.ch/1044/763382/_catid_1044_48/_method_download/_ page_1044_3/+Applying + Conversation + Analysis + to + Internet + Chat $\& \mathrm{hl}=\mathrm{zh}-\mathrm{CN} \& \mathrm{ct}=\mathrm{clnk} \& \mathrm{~cd}=2 \& \mathrm{gl}=\mathrm{sg}$

Tyler, T. R. (2002). Is the Internet changing social life? It seems the more things change, the more they stay the same. Journal of Social Issues, 58(1), 195-205.

Werry, C. C. (1996). Linguistic and interactional features of Internet relay chat. In S. Herring (Ed.), Computer mediated communication: Linguistic, social and cross-cultural perspectives (pp. 47-64). Amsterdam: John Benjamins. 